University of Nebraska - Lincoln

DigitalCommons@University of Nebraska - Lincoln

Bureau of Sociological Research - Faculty

Publications

Bureau of Sociological Research (BOSR)

October 2004

\title{
Chronic strain, daily work stress, and pain among workers with rheumatoid arthritis: Does job stress make a bad day worse?
}

Judith Fifield

University of Connecticut Health Center, MC-2918, Farmington, CT

Julia McQuillan

University of Nebraska - Lincoln, jmcquillan2@Unl.edu

Stephen Armeli

Psychology Department, 41 Park Row, Pace University, New York, NY

Howard Tennen

University of Connecticut Health Center, MC-6325, Farmington, CT

Susan Reisine

University of Connecticut Health Center, MC-3910, Farmington, CT

See next page for additional authors

Follow this and additional works at: https://digitalcommons.unl.edu/bosrfacpub

Part of the Sociology Commons

Fifield, Judith; McQuillan, Julia; Armeli, Stephen; Tennen, Howard; Reisine, Susan; and Affleck, Glenn, "Chronic strain, daily work stress, and pain among workers with rheumatoid arthritis: Does job stress make a bad day worse?" (2004). Bureau of Sociological Research - Faculty Publications. 14.

https://digitalcommons.unl.edu/bosrfacpub/14

This Article is brought to you for free and open access by the Bureau of Sociological Research (BOSR) at DigitalCommons@University of Nebraska - Lincoln. It has been accepted for inclusion in Bureau of Sociological Research - Faculty Publications by an authorized administrator of DigitalCommons@University of Nebraska - Lincoln. 


\section{Authors}

Judith Fifield, Julia McQuillan, Stephen Armeli, Howard Tennen, Susan Reisine, and Glenn Affleck 


\title{
Chronic strain, daily work stress, and pain among workers with rheumatoid arthritis: Does job stress make a bad day worse?
}

\author{
Judith Fifield, ${ }^{1}$ Julia McQuillan, ${ }^{2}$ Stephen Armeli, ${ }^{3}$ Howard Tennen, ${ }^{4}$ \\ Susan Reisine, ${ }^{5}$ and Glenn Affleck ${ }^{4}$ \\ 1 University of Connecticut Health Center, MC-2918, Farmington, CT 06030, USA \\ 2 University of Nebraska-Lincoln, 706 Oldfather Hall, Lincoln, NE 68588, USA \\ 3 Psychology Department, 41 Park Row, Pace University, New York, NY 10038, USA \\ 4 University of Connecticut Health Center, MC-6325, Farmington, CT 06030, USA \\ 5 University of Connecticut Health Center, MC-3910, Farmington, CT 06030, USA \\ Corresponding author: J. Fifield, email Fifield@NSO1.UCHC.EDU
}

\begin{abstract}
The structure of the job and the daily experience of work are challenges for workers with rheumatoid arthritis. Yet little is known about how these two factors interact to put workers with chronic pain at risk for worse pain on a given day. This exploratory 20 workday diary study of 27 workers with rheumatoid arthritis used hierarchical linear modeling to examine how the structure of the job and neuroticism moderate the relationship between daily undesirable work events (daily stressors), and pain reports within a day. On days with more undesirable work events compared to days with fewer events, individuals with jobs associated with job "strain" (high demand/low control) reported greater midday pain, irrespective of neuroticism and negative mood, than workers with other combinations of demand and control. These findings demonstrate the utility of analyzing fluctuating within-person relationships among pain, mood, and daily work stressors within the context of the structure of the job, and helps to explain why daily work stressors result in worse health outcomes for some but not all workers with RA.
\end{abstract}

Keywords: job strain, work stress, pain, rheumatoid arthritis

\section{Introduction}

Remaining active in paid work is important for people with Rheumatoid Arthritis (RA). Workers with RA report lower levels of emotional distress than non-workers (Fifield, Reisine, \& Grady, 1991; Fifield, Reisine, Pfieffer, \& Affleck, 1989), and workers who have been out of work and distressed find that their distress declines on return to work (White, Wrigley, LaGory, Fine, Maisiak, \& Straaton, 1995). Also, they often use their continued ability to work as a source of comfort (Affleck, Tennen, Pfeiffer, \& Fifield, 1987). Although paid work may be beneficial, the workplace can also be a source of unique challenges for many individuals with RA, demonstrated by the high rates of work disability (Albers et al., 1999; Allaire, Anderson, \& Meenan, 1996; Reisine, McQuillan, \& Fifield, 1995; Yelin, Nevitt, \& Epstein, 1980). 
This study brings together two contrasting explanations for the unique negative effects of paid work for individuals with RA. The first explanation focuses on situational or acute stress associated with the undesirable events that occur on a daily basis in the changing experience of work. A growing body of evidence indicates that such stressful daily circumstances are associated with daily mood (Affleck, Tennen, Urrows, \& Higgins, 1990; Armeli, Tennen, Affleck, \& Kranzler, 2000; Bolger, DeLongis, Kessler, \& Schilling, 1989), and illness symptoms (DeLongis, Folkman, \& Lazarus, 1988; Repetti, 1993; Stone, Reed, \& Neale, 1987). Studies show an association between minor stressful events and the course of RA as well, including symptoms such as pain (Affleck et al., 1990, 1994; Crosby, 1988; Parker et al., 1988), emotional well-being (Zautra, Burleson, Matt, Roth, \& Burrows, 1994), daily mood (Affleck et al., 1990) and indicators of disease activity (Mason, Anderson, Meenan, Weaver, \& Haralson, 1990; Smith \& Zautra, 2002). Few studies have examined the role of work events at the daily (cf. Affleck, Tennen, Urrows, \& Higgins, 1992) or weekly level (cf. Potter, Smith, Strobel, \& Zantra, 2002) in an arthritis population, although there is growing evidence in the general population that changes in daily mood are linked to daily work events (Barling \& Kryl, 1990; Bolger et al., 1989; Peeters, Buunk, \& Schaufeli, 1995; Reicherts \& Pihet, 2000; Repetti, 1993; Stewart \& Barling, 1996; van Eck, Nicolson, \& Berkhof, 1998).

In contrast, a second model focuses on the strain associated with more stable characteristics of the job such as high psychological demands and low levels of control (Karasek, 1979; Karasek \& Theorell, 1990). While the model of daily work stress posits that health outcomes such as pain and mood are linked to the momentary, undesirable events that happen in the course of a day at work, Karasek's job strain model posits that the structure of the job creates chronic conditions within which workers interact. The model has been widely tested, and despite mixed results from the proposed interaction of demands and control, new variations of the model focusing exclusively on control (Bosma et al., 1997) and a new operationalization of control (Wall, Jackson, Mullarkey, \& Parker, 1996), the job strain model is considered to be a primary model of chronic work stress with implications for both physical and mental health outcomes (Marmot, Theorell, \& Siegrist, 2002; Schnall, Schwarz, Landsbergis, Warren, \& Pickering, 1998; Schwartz, Pickering, \& Landsbergis, 1996; Soderfeldt et al., 1997) including musculoskeletal pain among workers (Nahit, Pritchaard, Cherry, Silman, \& Macfarlane, 2001; Pope, Silman, Cherry, Pritchaard, \& Macfarland, 2001).

The present, exploratory study investigates a multilevel (MLM) model of work stress that combines the chronic "strain" (high demand, low control) associated with the structure of work, the acute stress associated with undesirable daily work events, and neuroticism (Costa \& McCrae, 1985), a personality characteristic of the individual. This multilevel stress/strain model is based on the notion that the chronic strain associated with jobs that are demanding and lacking in control may make exposed workers more vulnerable to the daily stressors they experience, resulting in higher levels of pain within that day. They may be more vulnerable or reactive to daily work stressors, either because their coping capacity is diminished from the chronic "strain" of their work or because their job lacks access to coping resources such as control in their work (Pearlin \& Schooler, 1978). The model also recognizes that individuals vary in their reactivity to undesirable daily events, based on personality characteristics such as neuroticism that may moderate the stressor-health outcome relationship (Affleck et al., 1992, 1994; Bolger \& Schilling, 1991; Bolger \& Zuckerman, 1995; David et al., 1997; Persson \& Sahlberg, 2002). Despite evidence that chronic stress associated with conditions such as neighborhood environment exacerbates the effects of daily stressors (Caspi, Bolger, \& Eckenrode, 1987; Lepore, Evans, \& Palsane, 1991), multilevel models of work stress are rare (Grebner et al., 2004; Sonnentag, 2000), but may 
explain why undesirable work events result in worse health outcomes on a day-to-day basis for some but not all workers with RA.

The current study was undertaken to address this gap by exploring linkages among the relatively stable control and demand characteristics of the job associated with job strain, personality characteristics of the individual (neuroticism), undesirable daily work events, and pain and mood reports recorded on a daily basis in work event diaries. In particular, as Figure 1 shows, we examine the associations among pain, mood and undesirable daily work events in the narrow time frame between waking in the morning and taking a midday break at work (Level One).

We predict that on days when workers experience more undesirable events in the morning at work (stressors), they will report higher levels of pain within a short timeframe than on days with fewer undesirable events, controlling for pre-work pain and negative mood. This association is then examined within the context of the characteristics of the job and the person to test whether it is moderated by the chronic strain associated with the structure of the job (high demand/low control) or a personality characteristic of the individual (Level Two).

At Level Two, we predict that workers in "high strain" jobs will have even greater responses (higher levels of pain) to the undesirable events they encounter in the morning than their co-workers who encounter such events but are not in high strain jobs.

\section{Methods}

\subsection{Sample}

Patients with definite or classical RA, without major co-morbidity, were recruited from the practices of two community-based rheumatologists. To be included in the study, patients had to be between the ages of 20 and 65 years to avoid student workers and retirees, and had to be working the day shift for pay, outside the home, for at least 35 hours/week. Letters were sent from the rheumatologists explaining the study. Those interested in hear-

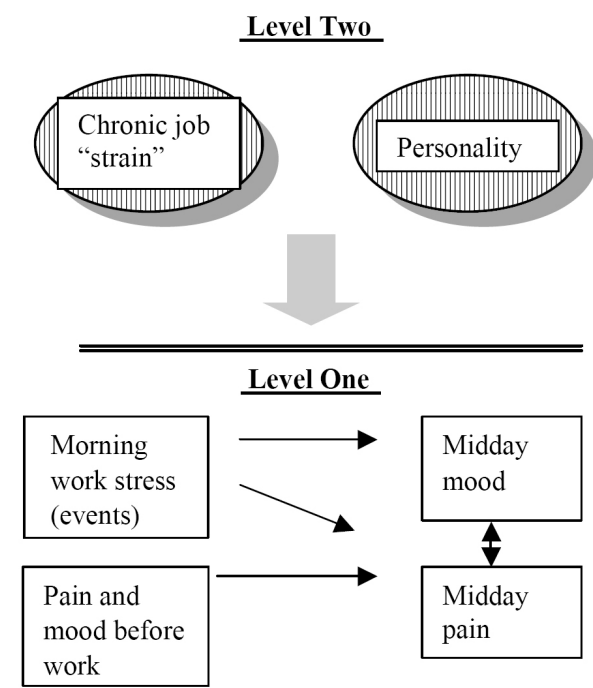

Figure 1. Multilevel work stress/strain model. 
ing more about the study $(N=46)$ were scheduled for an in-home interview and training session. As an incentive to encourage adherence to the 20-day daily protocol, participants were paid $\$ 2$ for each completed daily report form.

As Table 1 illustrates, the participants were primarily white, middle-aged women with at least a high school education and a moderate family and personal income in 1995. This sample is similar to samples found in other RA studies recruited from rheumatology practices (Reisine, Fifield, \& Winkelman, 1998). The high percentage of women in the sample is consistent with the higher prevalence of RA among women.

The majority of workers (not shown) were employed full-time and in occupations that ranged from semi-skilled to major professional, with most being either clerical or sales workers. About one-third of the sample had supervisory responsibilities. Most had benefits with full sick pay and health insurance, with fewer having paid meal breaks and only a minority being involved in profit sharing. The majority of workers had some kind of physical activity on the job: they were either involved in physical work or work that involved a computer, which constitutes physical work for people with RA due to the usual involvement of the hand joints.

\subsection{Procedures and measurement}

Daily measures of pain, mood and work events were obtained for 20 workdays with a daily work diary (DWD) that had been developed and validated with a sample of RA workers in an earlier phase of the study (Fifield, Affleck, \& Reisine, 1994; Fifield, Reisine, Affleck, \& Pasquale, 1996). Following the recommendation of Stone and Neale (1982) the DWD was in the form of a small booklet including a checklist of 86 work-related events

Table 1. Sample characteristics.

\begin{tabular}{|c|c|c|c|c|}
\hline & Mean & SD & Reported range & Percentage \\
\hline \multicolumn{5}{|l|}{ Demographic information } \\
\hline \multicolumn{5}{|l|}{ Age } \\
\hline Education (years) & 48 & 10 & $28-65$ & \\
\hline Family income (\$ US) & 15 & 2 & $12-17$ & \\
\hline$<30,000$ & & & & \\
\hline $30,000-49,000$ & & & & 35 \\
\hline$>50,000$ & & & & 54 \\
\hline \multicolumn{5}{|l|}{ Personal income (\$ US) } \\
\hline$<20,000$ & & & & 12 \\
\hline $20,000-29,000$ & & & & 20 \\
\hline $30,000-49,000$ & & & & 40 \\
\hline$>50,000$ & & & & 28 \\
\hline$\%$ Women & & & & 74 \\
\hline$\%$ White & & & & 93 \\
\hline \multicolumn{5}{|l|}{ Daily events and pain measures (average across days) } \\
\hline Pre-work pain (scored 0-100) & 27.71 & 20.48 & $0-80.00$ & 463 \\
\hline Midday pain (scored 0-100) & 27.76 & 20.20 & $0-99.00$ & 463 \\
\hline Prework negative mood (scored 0-3) & 0.28 & 0.43 & $0-2.56$ & 463 \\
\hline Midday negative mood (scored 0-3) & 0.25 & 0.39 & $0-2.00$ & 463 \\
\hline Morning undesirable events (scored 0-86) & 2.32 & 2.20 & $0-20.00$ & 463 \\
\hline \multicolumn{5}{|l|}{ Personality } \\
\hline Neuroticism (scored 0-3) & 1.43 & 0.52 & $0.58-2.50$ & 27 \\
\hline \multicolumn{5}{|l|}{ Structural work characteristics } \\
\hline Control at work (reversed) (scored 1-4) & 1.87 & 0.49 & $1.00-2.75$ & 27 \\
\hline Demand at work (reversed) (scored 1-4) & 1.91 & 0.56 & $1.00-3.00$ & 27 \\
\hline
\end{tabular}


as well as detailed instructions and a description of how to classify experiences using an event appraisal rating. Workers were asked to check off an item in the DWD during their midday break if it occurred that morning, and at the end of the workday if it occurred in the afternoon. Each item could be checked off once in each timeframe (morning and afternoon). They were then asked to rate or classify that experience in terms of its desirability/ undesirability on a 6-point bipolar adjective anchored scale with ratings from -3 (extremely undesirable) to +3 (extremely desirable) (Redfield \& Stone, 1979). This rating was included to identify the range of work events rated as desirable and undesirable by workers with RA. Participants were asked to record their pain and mood in the morning prior to leaving for work, during their midday break and again at the end of the workday before leaving work. To avoid transition from work to home effects, the "end of workday before leaving work" reports are not used in this analysis. This analysis is focused on the narrow time frame of pain reactivity to work stressors experienced during the morning at work, thus only the undesirable events (work stressors) that were recorded as occurring during the morning are included (Taylor, 1991).

Twenty work days was chosen as the recording period to: (1) provide an ample sampling of days $(n=20)$ for work stressors to occur; (2) offer sufficient within-person observations $(n=20)$ to provide reliable estimates and an adequate number of individuals to evaluate the effect of personal characteristics such as work demand and control; and (3) capture a time period that may parallel certain naturally occurring work stressors such as monthly quotas, Blue Mondays and pay days.

A procedure similar to other studies (Schanberg, Anthony, Gil, \& Maurin, 2003) was followed to enhance and track adherence to the daily diary protocol. Workers were visited at home by the research assistant one or two days prior to the first day of recording for an orientation to the daily work diary and a structured interview about their work and their personality. Participants were given 20 diaries and 20 stamped envelopes and were encouraged to follow the same schedule each day and to mail their diaries in the next morning's mail on 20 sequential workdays. The cover of each DWD was stamped with a calendar and participants were asked to circle the date on the calendar corresponding to the recording day. The research assistant visited the post office daily to retrieve the mail. Participants were called on the second day of recording and then on the first day of each of the next three recording weeks to enhance adherence. Additional calls were made when there was an interruption in the return of diaries for any given individual. This reminder and tracking procedure resulted in most workers completing their 20-day diary series in sequence. Only 5 work days (1\%) were missed (no diary returned) over the 540 possible person days and, in most cases, workers continued on to complete their 20-day series.

The morning's undesirable work events were obtained from each participant's DWD. The events were grouped into 11 domains concerning: (1) people who supervise, manage or employ you; (2) co-workers or colleagues; (3) people you supervise or who are subordinate to you; (4) others with whom you interact on the job; (5) gatherings with people at work for work-related discussion or process; (6) your personal performance; (7) physical activity that is a part of the workday; (8) the office environment; (9) job/ financial security; (10) work routine/pace/schedule; (11) other work-related events (Fifield et al., 1994, 1996). Examples of work events that were rated as undesirable include: "She/he (supervisor) assigned an unusually disagreeable or difficult task to me"; "I had to interact with a difficult client, e.g. intimidating, unhappy or uncooperative"; "An unexpected meeting was called (or no time to prepare for a meeting)"; "I had an argument with someone"; "I participated in some activity using my hands that was more physically challenging than usual (e.g. typing, filing lifting carrying, etc.)"; "The air temperature became less comfortable than 
usual"; and "I parked in a less convenient space." Undesirable events were the number of events rated as slightly $(-1)$, moderately $(-2)$ or extremely $(-3)$ undesirable.

Pre-work and Midday negative mood were measured by three scales (anxious, depressed, and hostile, all rated 0-3) from the Profile of Mood States-B (POMS-B, Lorr \& McNair, 1982). Before leaving for work in the morning participants were asked to report how they were feeling at the moment on the 18-item scale. At midday they were asked to report how they had been feeling over the morning. The full POMS-B measures both negative and positive mood and has been used in previous research with RA patients (Affleck et al., 1990, 1992). Evidence for the instrument's concurrent and predictive validity comes from a number of investigations of seriously ill patients and their family members (Affleck, Tennen, Allen, \& Gershman, 1986; Affleck, Tennen, \& Gershman, 1985; Pfeiffer, Affleck, \& Tennen, 1986). The a reliability of the midday POMS-B negative affect scale showed high internal consistency on three separate reporting days chosen the beginning, middle and end of the reporting period ( $\alpha$ reliability $=.89, .83$, and .93 , respectively). The mean of the three negative mood subscales (anxious, depressed, and hostile) for both pre-work and midday was used in this analysis.

Workers were asked to report their joint pain upon awakening and then during their midday break. Upon awakening in the morning they were asked, "thinking about your arthritis pain in general, on a scale of 0 to 100 with 0 being the least pain possible and 100 being the most, how much pain do you feel now?" At midday they were asked to report their joint pain over the morning at work. Such scales have been shown to be sensitive self-reports of pain in RA (Meenan, Yelin, Nevitt, \& Epstein, 1981).

Job strain, indicated by low control and high demand, was measured during the inhome interview with items developed by Karasek and Theorell (1990). Control was an equally weighted sum of two subscales: (a) Skill Discretion, and (b) Decision Authority. Skill Discretion was measured by the sum of six questions that asked how much workers agreed with the following statements on a scale from 1 (strongly agree) to 4 (strongly disagree): (1) "My job requires that I keep learning new things." (2) "I get to do a number of different things on my job." (3) "My job requires that I do the same things over and over." (4) "My job requires a high level of skill." (5) "My job lets me use my skills and abilities." (6) "My job requires that I be creative." Question 3 was reverse coded so that a score of 1 equals high decision authority. Using the same response categories of "strongly agree" to "strongly disagree," decision authority was measured by six questions: (1) "It is basically my own responsibility to decide how my job gets done." (2) "I have the freedom to decide what I do on the job." (3) "I determine the speed at which I work." (4) "I decide whom I work with on my job." (5) "I decide when I take breaks." (6) "I decide when to come in to work." All items were scored within the range 1 to 4 .

Demand (scored 1-4) was measured by the sum of five questions that asked how often (always, sometimes, rarely, or never) the following five statements were true. (1) "My job requires that I work fast." (2) "My job requires that I work hard." (3) "I am never asked to do excessive amounts of work." (4) "I do not have conflicting demands placed on me." (5) "I have enough time to get the job done." Questions 3, 4, and 5 were reverse coded so that a score of 1 equals high demand. Both the control and demand scales were recoded so that high scores in all of the analyses and tables indicate high demand or control.

Neuroticism was measured by the 48-item Neuroticism scale of the NEO Personality Inventory (Costa \& McCrae, 1985). The NEO-PI with five response categories from strongly disagree to strongly agree, measures six dimensions of neuroticism indicating a predisposition to experience depression, chronic anxiety, chronic hostility, self-consciousness, im- 
pulsiveness, and vulnerability. In this sample the $\alpha$ reliability of these sub-scales ranged from .65 to .88 .

\subsection{Multilevel data and models}

We collected multiple within-day reports across days and individuals, therefore the data are multi-level (days nested within-persons). We examined within-person day-level associations (level 1) and the moderating effect of between-person characteristics on those associations (level 2). We used HLM5 (Raudenbush, Bryk, Cheong, \& Congdon, 2000) to assess: (a) whether undesirable morning work events (UWE) and pre-work pain (PWP), controlling for pre-work negative mood (PWNM), have a partial effect on that day's midday reports of negative mood over the morning at work (MNM) and midday work pain over the morning (MWP); and (b) how these within-person associations varied as a function of chronic strainproducing jobs (demand and control separately and in combination) and neuroticism. This analytic strategy appropriately accommodates the unbalanced, non-independent, nested data structures commonly found in daily studies of stress (Bolger \& Zukerman, 1995; Gunthert, Cohen, \& Armeli, 1999). It also follows Raudenbush and Bryk's (2002) suggestions to first establish the level 1 model (pain and mood reactivity to daily stressors) before adding level 2 variables (moderators of pain/mood reactivity such as chronic "strain").

In the final full model we simultaneously estimated two sets of regression equations: the within- and between-person models (Bryk \& Raudenbush, 1992; Kreft, Leeuw, \& Aiken, 1995). The primary focus of this analysis is on the moderating effect of chronic strain and personality on the relationships between daily events and daily pain reports, therefore we followed Hofmann and Gavin (1998) by group-mean-centering all level 1 predictors.

Most $(96.4 \%)$ of the work events recorded occurred between Monday and Friday and therefore we examined only these days. In all analyses, we controlled for day of the week by including four uncentered dummy variables (with Friday as the reference day) to model day of the week (West \& Hepworth, 1991). The day variables (time-varying covariates) were included in all the analyses and modeled as fixed effects (no level 2 variance component) (Bryk \& Raudenbush, 1992, p. 151).

\section{Results}

Thirty (out of a possible 46) workers with rheumatoid arthritis were recruited, giving a response rate of $65 \%$. Some $27(90 \%)$ of the workers completed the study for a total of $N=540$ potential person days (27 participants and 20 days). One participant missed one day and another missed four days of daily reporting. Participants reported events on 40 weekend workdays, which were excluded from this analysis and 31 days were dropped due to missing values. Thus, $N=463$ daily diary days were used in the analysis. For summary purposes, daily pre-work and midday pain reports, pre-work and midday negative mood, and morning work events were averaged across all days and persons $(N=463$ person-days) (Table 1). Although pain ratings could range from $0-100$, no one in the sample recorded a pre-work pain score over 80 , nor a midday pain score over 99 . The aggregated means and standard deviations for pre-work pain $(\mathrm{M}=27.71, \mathrm{SD}=20.48)$ and midday pain $(\mathrm{M}=27.76, \mathrm{SD}=20.20)$ were very similar. The same was true for pre-work and midday negative mood scores; both indicated low levels of negative mood (mean $=.28, \mathrm{SD}=.43$ for pre-work and mean $=0.25, \mathrm{SD}=0.39$ for midday). On most mornings participants experienced an average of 2.36 undesirable work events (with a high of 20). 
Neuroticism, control, and demand were all measured at the person level. Average neuroticism scores were at the middle of the actual range from .58 to $2.50(\mathrm{M}=1.43)$, but below the midpoint of the theoretical range ( 1 to 5 ). Control and demand scale scores were summed and averaged to retain the original theoretical range, reverse coded, of 4 (high control, high demand) to 1 (low control, low demand). No actual scores reached the theoretical limits ( mean control $=1.87$, actual range from 1 to 2.75 ; mean demand $=1.91$, actual range from 1 to 3). In the multi-level analysis control and demand were entered as $z$-scores.

\subsection{Aggregate level correlations}

We also aggregated the within-person variables by creating average pre-work pain, midday pain, pre-work negative mood, and midday negative mood scores for each person across their 20 days. Table 2 contains the bivariate correlations from these variables. We examined these correlations primarily to contrast them with the within and between person associations in the HLM analyses. Low statistical power and within-person dependence make interpretations of the significance of the results challenging (Raudenbush \& Bryk, 2002). Despite lower power to detect an effect, there was a strong positive association between pre-work pain and midday pain at the aggregate level. All of the other variables were associated with midday pain in the expected directions. Pre-work and midday negative mood had a strong positive association. Neuroticism was associated with higher levels of negative mood. Demand and Control showed a moderate negative association $(r=-.38)$, suggesting that individuals with more control at work experienced somewhat less workrelated demand. At the aggregate bivariate level, the morning's undesirable work events, chronic strain-producing jobs (control/demand), midday mood, and personality indicators had weak, non-significant associations with aggregate pre-work or midday pain.

\subsection{Within-person day level associations}

The next step in the analysis was taken to identify whether individual workers differed in the way their midday pain reports related to their midday mood, and to their experience of undesirable morning work events within a day, controlling for pre-work negative mood. Table 3 presents the mean within-person intercepts and slopes for the associations among

Table 2. Intercorrelations among aggregate pain, daily event, mood, personality, and work structure variables $(N=27)$.

\begin{tabular}{|c|c|c|c|c|c|c|c|}
\hline & $\begin{array}{c}\text { Midday } \\
\text { pain }\end{array}$ & $\begin{array}{c}\text { Morning } \\
\text { undesirable } \\
\text { events }\end{array}$ & $\begin{array}{c}\text { Pre-work } \\
\text { pain }\end{array}$ & $\begin{array}{c}\text { Pre-work } \\
\text { negative } \\
\text { mood }\end{array}$ & $\begin{array}{c}\text { Midday } \\
\text { negative } \\
\text { mood }\end{array}$ & $\begin{array}{c}\text { Work } \\
\text { control }\end{array}$ & $\begin{array}{l}\text { Work } \\
\text { demand }\end{array}$ \\
\hline $\begin{array}{l}\text { Morning } \\
\text { undesirable events }\end{array}$ & -.117 & - & & & & & \\
\hline Pre-work pain & $.97^{* * *}$ & -.12 & - & & & & \\
\hline $\begin{array}{l}\text { Pre-work negative } \\
\text { mood }\end{array}$ & -.13 & -.24 & -.10 & - & & & \\
\hline $\begin{array}{l}\text { Midday negative } \\
\text { mood }\end{array}$ & -.08 & -.27 & -.03 & $.96^{* * *}$ & & & \\
\hline $\begin{array}{l}\text { Work control } \\
\text { (high/4) }\end{array}$ & -.16 & -.13 & -.07 & -.05 & -.04 & - & \\
\hline $\begin{array}{l}\text { Work demand } \\
\text { (high/4) }\end{array}$ & -.05 & .12 & -.04 & -.02 & .03 & $-.38^{*}$ & - \\
\hline Neuroticism & .26 & -.00 & .30 & $.52^{* *}$ & $.54^{* *}$ & -.05 & -.13 \\
\hline
\end{tabular}

${ }^{*} p<.05 ;{ }^{* *} p<.01 ;{ }^{* * *} p<.001$. 
Table 3. Pooled $(n=27)$ within-person associations (Level $1 n=463$ ) of negative midday mood and midday pain with pre-work pain, pre-work negative mood and undesirable morning events.

\begin{tabular}{|c|c|c|c|c|c|c|c|c|c|}
\hline \multirow{3}{*}{$\begin{array}{l}\text { Average within-person } \\
\text { coefficients }\end{array}$} & \multirow{2}{*}{\multicolumn{3}{|c|}{$\frac{\text { Midday negative mood }}{\text { Model } 1 \dagger}$}} & \multicolumn{6}{|c|}{ Midday pain } \\
\hline & & & & \multicolumn{3}{|c|}{ Model 2} & \multicolumn{3}{|c|}{ Model 3} \\
\hline & $\mathrm{B}$ & SE & $t$ & B & SE & $t$ & $\mathrm{~B}$ & SE & $t$ \\
\hline Intercept & 0.24 & 0.05 & $4.71^{* * *}$ & 27.69 & 3.39 & $8.16^{* * *}$ & 27.73 & 3.41 & $8.13^{* * *}$ \\
\hline Pre-work pain & -0.00 & 0.00 & -0.11 & 0.73 & 0.13 & $5.82^{* * *}$ & 0.72 & 0.13 & $5.71^{* * *}$ \\
\hline Undesirable work events & 0.01 & 0.01 & $2.41^{*}$ & 0.67 & 0.34 & 1.96 & 0.60 & 0.34 & 1.75 \\
\hline Pre-work negative mood & 0.57 & 0.06 & $9.43^{* * *}$ & 1.33 & 0.95 & 1.40 & -1.38 & 1.05 & -1.31 \\
\hline Midday negative mood & - & - & - & - & - & - & 5.11 & 1.33 & $3.84^{* * *}$ \\
\hline
\end{tabular}

Note: We controlled for day of the week at level 1 in all of the analyses. The coefficients were estimated from 463 observations across 27 study participants.

${ }^{*} p<.05 ;{ }^{* *} p<.01 ;{ }^{* * *} p<.001$.

† In model 1, the intercept has an error term; in models 2 and 3, the intercept, pre-work pain, and morning undesirable events have error terms.

the daily variables. We first regressed midday negative mood on pre-work pain and undesirable morning work events, controlling for pre-work negative mood (Table 3, first column). Negative mood before going to work and undesirable morning events at work each showed independent associations with midday negative mood. The within-person variables were centered around each person's own mean, therefore the intercept is the average of all 27 intercepts when each person's score on the other variables equals 0 (the mean of those variables across each person's daily reporting). Although at just less significant than the conventional .05, undesirable work events in the morning tended also to be positively associated with midday pain reports, even controlling for pre-work negative mood (Table 3, second column). To determine if this association was an artifact of greater pre-work pain leading to the perception of more undesirable events at work, we regressed undesirable work events on pre-work pain, and found no association $(B=-0.01, \mathrm{SD}=1.006, \mathrm{df}=$ $26, p=.324)$. The positive association between undesirable work events and midday pain suggests that undesirable work events are associated with an increase in negative mood and pain over the morning. Days starting off with greater pre-work pain and more undesirable work events were associated with greater midday negative mood and more midday pain compared to days without such morning stressors, controlling for each person's mood at the beginning of the day. Midday mood showed a significant positive association with midday pain, and only slightly diminished the effects of pre-work pain and undesirable events on midday pain (Table 3, column 3).

The second step in the analysis tested whether the chronic strain associated with the demands and control of the job, and the predisposition to react to negative events (neuroticism), moderated the within-person daily associations between undesirable events and pain at midday. We regressed the level 1 pain, mood, and event parameters (intercepts and slopes) on neuroticism, demands, control, and the interaction of demands and control (Table 4). All of the between-person variables were standardized, therefore a zero indicates average neuroticism, control, and demands for this sample. Therefore, all of the intercepts for the level 2 models indicate the average pain for people with average neuroticism, control, and demand.

The within-person association between pre-work pain and midday pain varied as a function of the structure of the job, such that individuals reporting low control and low 
Table 4. Multi-level regression results for cross-level interactions:

midday pain with pre-work pain, pre-work negative mood, undesirable morning work events, midday negative mood by chronic strain (control and demand), and personality (neuroticism).

\begin{tabular}{|c|c|c|c|}
\hline & \multicolumn{3}{|c|}{ Midday pain $†$} \\
\hline & $\mathrm{B}$ & SE & $t$-value \\
\hline \multicolumn{4}{|l|}{ 1st-level intercept (average midday pain), $b_{0}$} \\
\hline Intercept, $\gamma_{00}$ & 26.49 & 3.890 & $6.80^{* *}$ \\
\hline Effect of neuroticism $\gamma_{01}$ & 5.02 & 3.73 & 1.35 \\
\hline Effect of control (high $=$ high) $\gamma_{02}$ & -4.45 & 4.18 & -1.06 \\
\hline Effect of demand (high $=$ high) $\gamma_{03}$ & -2.11 & 3.87 & -0.54 \\
\hline Effect of control $\times$ demand interaction $\gamma_{04}$ & -3.33 & 4.52 & -0.74 \\
\hline \multicolumn{4}{|l|}{ 1st-level slope (pre-work pain to midday pain, $b_{1}$ ) } \\
\hline Slope on average $\gamma_{10}$ & 0.84 & 0.14 & $5.90^{* * *}$ \\
\hline Effect of neuroticism $\gamma_{11}$ & -0.14 & 0.13 & -1.07 \\
\hline Effect of control (high $=$ high) $r_{12}$ & -0.14 & 0.15 & -0.98 \\
\hline Effect of demand (high $=$ high) $\gamma_{13}$ & -0.11 & 0.15 & -0.70 \\
\hline Effect of control $\times$ demand $\gamma_{14}$ & 0.37 & 0.17 & $2.13^{*}$ \\
\hline \multicolumn{4}{|c|}{ 1st-level slope (undesirable work events to midday pain, $b_{2}$ ) } \\
\hline Slope on average $\gamma_{20}$ & 0.07 & 0.38 & 0.120 \\
\hline Effect of neuroticism $\gamma_{21}$ & -0.16 & 0.35 & -0.445 \\
\hline Effect of control (high $=$ high) $\gamma_{22}$ & -0.74 & 0.340 & -1.87 \\
\hline Effect of demand (high $=$ high) $\gamma_{23}$ & -0.08 & 0.36 & -0.21 \\
\hline Effect of control $\times$ demand $\gamma_{24}$ & -1.21 & 0.44 & $-2.78^{*}$ \\
\hline \multicolumn{4}{|c|}{ 1st-level slope (pre-work negative mood to midday pain, $b_{3}$ ) } \\
\hline Slope on average $\gamma_{40}$ & 1.30 & 2.45 & 0.53 \\
\hline Effect of neuroticism $\gamma_{41}$ & -2.20 & 2.60 & -0.85 \\
\hline Effect of control (high $=$ high) $\gamma_{42}$ & 3.85 & 2.36 & 1.63 \\
\hline Effect of demand (high $=$ high) $\gamma_{43}$ & 2.76 & 2.267 & 1.22 \\
\hline Effect of control $\times$ demand $\gamma_{44}$ & 5.27 & 3.456 & 1.53 \\
\hline \multicolumn{4}{|c|}{ 1st-level slope (midday negative mood to midday pain, $b_{4}$ ) } \\
\hline Slope on average $\gamma_{30}$ & 4.23 & 2.00 & 1.93 \\
\hline Effect of neuroticism $\gamma_{31}$ & -0.25 & 2.08 & -0.12 \\
\hline Effect of control (high $=$ high) $\gamma_{32}$ & -1.70 & 2.13 & -0.80 \\
\hline Effect of demand (high $=$ high) $\gamma_{33}$ & -2.72 & 2.16 & -1.26 \\
\hline Effect of control $\times$ demand $\gamma_{34}$ & -1.83 & 3.23 & -0.57 \\
\hline
\end{tabular}

Note. We controlled for day of the week at level 1 in all of the analyses. The coefficients were estimated from 463 observations across 27 study participants.

${ }^{*} p<.05 ;{ }^{* *} p<.01 ;{ }^{* * *} p<.001$.

$\dagger$ The intercept, pre-work pain, and undesirable events have error terms.

demand work situations showed the strongest within-person associations. That is, on high pre-work pain days, individuals with low control and low demand work situations were more likely to experience high midday pain compared to their counterparts in other work situations (Figure 2).

The within-person association between undesirable work events in the morning and midday pain reports also varied as a function of the structure of the job. Specifically, individuals with jobs characterized as high demand/low control (thought to produce chronic strain) demonstrated the strongest positive associations between undesirable work events and midday pain. That is, on days with more undesirable work events compared to days with fewer events, individuals with high demand/low control reported greater midday pain, irrespective of neuroticism (Figure 3). Individuals in high demand but high control situations had even lower pain as undesirable events increased. There was very little change in pain among those in low demand work situations (regardless of the level of control in their job situation). 


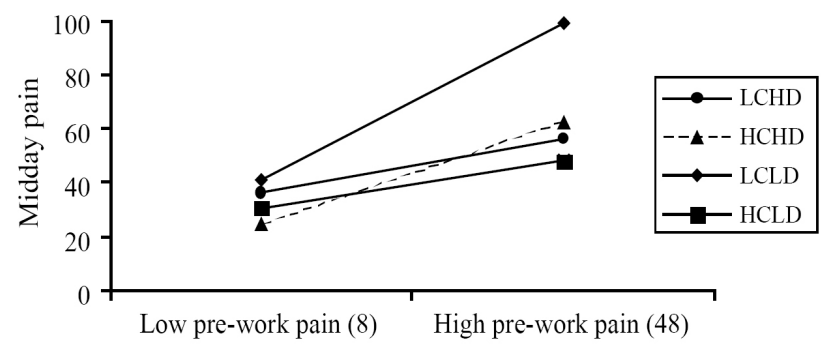

Figure 2. Moderating effect of job strain (control/demand) on the within-person pre-work painmidday pain association. $\mathrm{L}=$ low; $\mathrm{H}=$ high; $\mathrm{C}=$ control; $\mathrm{D}=$ demand.

\section{Discussion}

This exploratory study was undertaken to explore the utility of a multilevel model to identify conditions in paid work that may make workers with rheumatoid arthritis more vulnerable to worse health outcomes on a day-to-day basis. In particular we explored whether the chronic "strain" associated with jobs that are high in demands and low in control increases workers' reports of pain and mood at midday on a day when they experience more undesirable work events after they arrive at work. We also considered whether a personality attribute of the individual (neuroticism) might moderate the association. This was done to bring the individual and the changing daily experience of work into models of chronic job strain that view the structure of work as a chronic stressor. At the same time it was undertaken to bring a relatively stable social context to the daily work event perspective on work stress that usually stays at the level of the individual and the day.

We found support for the multilevel model. First, we found support for the notion that daily undesirable work events are correctly specified as fluctuating from day-to-day within individuals. To assess the amount of within-and between-person stability/instability in undesirable morning work events we used the MLM analysis to estimate a model with undesirable morning work events as the outcome and an error term for the intercept. The intercept for this model indicated that, on average, workers experienced two undesirable morning work events a day $(\mathrm{B} 0=2.31, \mathrm{SE}=.24, p<.001)$. The variance component for the intercept $\left(\mathrm{U} 0=1.38, \mathrm{SD}=1.17, \chi^{2}=200.72, \mathrm{df}=27, p<.001\right.$ ) was smaller than the variance component for the within-person error term $(R=3.50, \mathrm{SD}=1.87)$, therefore $82 \%$ of the variance in undesirable morning work events was within people, indicating considerable instability day-to-day despite permanent control/demand work structures.

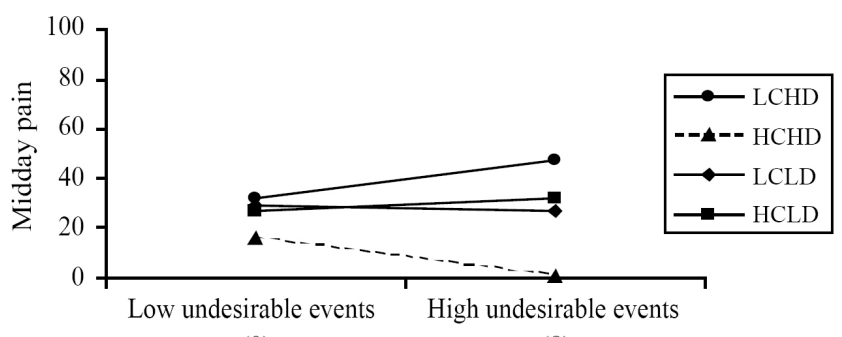

(0)

(8)

Figure 3. Moderating effect of job strain (control/demand) on the within-person undesirable morning work events-midday pain associations. $\mathrm{L}=$ low; $\mathrm{H}=$ high; $\mathrm{C}=$ control; $\mathrm{D}=$ demand. 
Second, in this sample of workers with RA, undesirable morning work events and midday mood independently predicted changes in pain over the morning, and the associations varied as a function of job characteristics thought to result in chronic strain. Specifically, the effect of undesirable work events emerged only under conditions of job strain as proposed by Karasek (1979). For workers with high demand and low control jobs (high strain), pain at midday was higher on days when they encountered more undesirable work events in the morning, irrespective of any predisposition to be more reactive to events due to neuroticism or to negative mood at midday. The contrast to workers in lower "strain" situations is clearly seen in Figure 3. Some workers even appear to have had a protective effect from their work in that those with high control and high demand jobs (Karasek and Thoerell's (1990) "active" jobs, thought to be "without negative psychological strain") showed a reduction in pain by midday, even on days with more negative events. The lack of pain reactivity for those with high levels of neuroticism is consistent with other RA studies, where neuroticism has not moderated the relationship between disease activity and symptom reports (Smith, Wallston, \& Dwyer, 1995), undesirable daily events and daily pain (Affleck et al., 1994) or workplace stressors and weekly arthritis symptoms (Potter et al., 2002). While neuroticism may well moderate the relationship between daily events and mood (Bolger \& Zuckerman, 1995), it does not appear to moderate the relationship between undesirable events and pain in RA patients.

In addition, while not predicted, we found that participants in low control and low demand jobs showed the strongest within-person associations between pre-work pain and midday pain. That is, on high pre-work pain days, workers in Karasek and Theorell's (1990) "passive job" category were more likely to have high midday pain compared to people in other work situations (Figure 2). Furthermore, individuals in high control and low demand ("low strain") situations appear to have the weakest association between prework pain and midday pain. This suggests that being able to experience greater control and fewer demands than workers in the average situation provides a mechanism through which the perception of pain is reduced. In contrast, workers in low control, low demand work, are not afforded that protection.

This study also demonstrates the utility of multi-level research designs. The withinperson association between pain recorded before work and pain recorded at midday is notably different from the between-person aggregate association, which approached a perfect correlation. Specifically, pre-work pain only accounted for $47 \%$ of the within-person variance in midday pain compared to the $97 \%$ shared variance at the aggregate level. These differences in patterns of association highlight the importance of separating levels of analysis, and not assuming that what holds at the between-person level will be true at the within-person level of analysis. Similarly, very little about work (neither demands, control, nor undesirable daily events) was associated with pain at the aggregate level (between-person), where undesirable work events during the morning were not correlated with either pre-work, nor midday pain reports at midday. However, within-person analyses revealed the association between undesirable morning work events, pain and negative mood during the workday. Thus, this multilevel stress/strain model adds importantly to the work of Grebner et al. (2004), who recently showed that chronic conditions set the stage for greater reactivity to stressful encounters on the daily level among young workers without chronic disease. As they point out, the Karasek job strain model may be highly relevant for explaining worse outcomes from situational or daily stressors, whereas it has had mixed success in predicting chronic stress outcomes (Marmot et al., 2002). These analyses also add to the literature on job strain showing that while the characteristics of work may 
be rather stable and unchanging, the effect on the health of the individual worker may fluctuate from day-to-day, based on the events of the day.

Although the relatively low statistical power in this study failed to detect additional moderating effects of the within-person associations, our sample size (20 person-days within 27 participants) comes close to Kreft's (1996) recommendation of a sample with at least 30 participants and at least 30 observations per participant. In a simulation study, Maas and Hox (2002) found that within-person estimates (level 1) and fixed between-person estimates (level 2) are unbiased with 30 participants, but that significance tests of unfixed between-person coefficients (such as demand and control) are biased (9\% fall outside the confidence interval of the true coefficient). Further research with a minimum of 30 study participants is necessary to increase confidence that the null findings in this sample are accurate, and this study must therefore be regarded as exploratory.

These findings, and recent modifications to the measurement of job strain, raise questions that must be addressed before new models or interventions can be developed. First, it is not clear just how the control and demand in a job contribute to the response of workers to undesirable events. For instance, having challenging, stimulating work and having control over one's pace, schedule, and activities may give one a feeling of control over the events that occur, as Karasek and Theorell (1990) suggest, or it may offer real options for action that help to neutralize the effect of a negative event. Workers in structural locations that offer such control may also be individuals who happen to possess a personal sense of control irrespective of their social location (see Tennen et al., 1992 for a review of this literature). The effortreward imbalance model of chronic work stress may provide insights into some of these issues, as it includes both a structural and a personal dimension (Siegrist, 2002). Future studies should consider using both the job strain and the effort-reward imbalance models to increase our understanding of the mechanisms behind the stress/strain model. Finally, the model may be improved by adopting the reconceptualization of the control dimension of job strain as suggested by Wall et al. (1996) to remove the confounding concept of job complexity.

This study explored the associations among events, mood, and pain reports within a day without the benefit of electronic prompt technology to promote and verify adherence to the within-day reporting schedule (Tennen \& Affleck, 2002). While participants had inhome orientations to the procedures, received periodic telephone calls to enhance adherence, and were provided with well-marked daily diaries, we cannot be sure that morning reports were actually recorded in the morning and midday reports at midday, although we are confident that the daily reports were reliable. However, it is unlikely that workers in chronic strain situations would systematically record undesirable events, pain and mood reports to reveal the moderating effects found in this analysis. This would require that only these workers systematically "misremembered" their pain to be higher at midday, only on the days when they experienced more negative events. While it is unlikely that this occurred, a future test of the multilevel work stress/strain model should be undertaken with more attention to the prompting and verifiable recording of symptom reports and experienced events.

Although we demonstrated a possible moderating effect for control and demands in paid work on the event-mood relationship within a day, we have used a widely-tested model that views undesirable events as stressors that lead to outcomes such as changes in mood and pain (Affleck et al., 1990, 1994; Crosby, 1988; Mason et al., 1990; Parker et al., 1988; Smith \& Zautra, 2002; Zautra et al., 1994). However, we cannot rule out the fact that negative mood states at midday might have enhanced the recall of the morning's negative events (Blaney, 1986; Bower, 1981). Finally, we did not examine how chronic strain 
and acute, daily stress work together to affect pain and mood across days. As Affleck et al. $(1990,1994)$ have shown, it is a mistake to abstract one day out of the week, month or life of an individual with a disease like RA that changes from day-to-day. Future studies must examine how both paid and unpaid work events pile up over the week, the month, the year and with what effect on health. Such studies might offer new insights into factors that contribute to flaring up of the condition, work loss and ultimately withdrawal from work.

\section{References}

Affleck, G., Tennen, H., Allen, D., and Gershman, K. (1986). Perceived social support and maternal adaptation during the transition from hospital to home care of high-risk infants. Infant Mental Health Journal, 7, 6-18.

Affleck, G., Tennen, H., and Gershman, K. (1985). Cognitive adaptations to a high-risk infant: The search for meaning, mastery, and protection from future harm. American Journal of Mental Deficiency, 89, 653-656.

Affleck, G., Tennen, H., Pfeiffer, C., and Fifield, J. (1987). Appraisals of control and predictability in adapting to a chronic disease. Journal of Personality and Social Psychology, 52, 273-279.

Affleck, G., Tennen, H., Urrows, S., and Higgins, P. (1990). Temporal patterning of stressful events and RA disease activity: A prospective study of 3000 person-days. Arthritis Care and Research, 3, S9.

Affleck, G., Tennen, H., Urrows, S., and Higgins, P. (1992). Neuroticism and the pain-mood relation in rheumatoid arthritis: Insights from a prospective daily study. Journal of Consulting and Clinical Psychology, 60, 119-126.

Affleck, G., Tennen, H., Urrows, S., and Higgins, P. (1994). Person and contextual features of daily stress reactivity: Individual differences in relations of undesirable daily events with mood disturbance and chronic pain intensity. Journal of Personality and Social Psychology, 66, 329-340.

Albers, J. M., Kuper, H. H., Van Riel, P. L., Prevoo, M. L., Van't Hof, M. A., Van Gestel, A. M., and Severens, J. L. (1999). Socio-economic consequences of rheumatoid arthritis in the first years of the disease. Journal of Rheumatology, 38, 423-430.

Allaire, S. H., Anderson, J. J., and Meenan, R. F. (1996). Reducing work disability associated with rheumatoid arthritis: Identification and additional risk factors and persons likely to benefit from intervention. Arthritis Care and Research, 9, 349-357.

Armeli, S., Tennen, H., Affleck, G., and Kranzler, H. R. (2000). Does affect mediate the association between daily events and alcohol use? Journal of Studies on Alcohol, 61, 862-871.

Barling, J. and Kryl, I. (1990). Moderators of the relationship between daily work stressors and mood. Work and Stress, 4, 319-329.

Blaney, P. H. (1986). Affect And Memory: A Review. Psychology Bulletin, 99, 229-246.

Bolger, N., Delongis, A., Kessler, R. C., and Schilling, E. A. (1989). Effects of daily stress on negative mood. Journal of Personality and Social Psychology, 57, 808-818.

Bolger, N. and Schilling, E. A. (1991). Personality and the problems of everyday life: The role of neuroticism in exposure and reactivity to daily stressors. Journal of Personality, 59, 335-386.

Bolger, N. and Zuckerman, A. (1995). A framework for studying personality in the stress process. Journal of Personality and Social Psychology, 69, 890-902.

Bosma, H., Marmot, M. G., Hemingway, H., Nicholson, A. C., Brunner, E., and Stansfeld, S. A. (1997). Low job control and risk of coronary heart disease in Whitehall II (prospective cohort) study. British Medical Journal, 314 (7080), 558-565.

Bower, G. H. (1981). Mood and memory. American Psychologist, 36, 129-148.

Bryk, A. S. and Raudenbush, S. W. (1992). Hierarchical Linear Models: Applications and Data Analysis Methods. Newbury Park, CA: Sage Publications. 
Caspi, A., Bolger, N., and Eckenrode, J. (1987). Linking person and context in the daily stress process. Journal of Personality and Social Psychology, 32(1), 184-195.

Costa, P. T., Jr. And McCrae, R. R. (1985). The NEO Personality Inventory Manual. Odessa, FL: Psychological Assessment Resources.

Crosby, L. J. (1988). Stress factors, emotional stress and rheumatoid arthritis disease activity. Journal of Advanced Nursing, 13, 452-461.

David, J. P., Green, P. J., and Suls, J. (1997). Differential roles of neuroticism, extraversion and event desirability of mood of daily life: An integrative model of top-down and bottom-up influences. Journal of Personality and Social Psychology, 73, 149-159.

Delongis, A., Folkman, S., and Lazarus, R. S. (1988). The impact of daily stress on health and mood: Psychological and social resources as mediators. Journal of Personality and Social Psychology, 54, 486-496.

Fifield, J., Affleck, G., and Reisine, S. (1994). Identifying stressful daily events in paid work events for people with RA. Arthritis and Rheumatism, 37(9), S159.

Fifield, J., Reisine, S., Affleck, G., and Pasquale, K. (1996). Structured risk and daily work events among workers with RA. Arthritis and Rheumatism, 39(9), S313.

Fifield, J., Reisine, S., and Grady, K. (1991). Work disability and the experience of pain and depression in RA. Social Science and Medicine, 33, 579-585.

Fifield, J., Reisine, S., Pfeiffer, C., and Affleck, G. (1989). Workplace disability: Gender, technology, and the experience of Rheumatoid Arthritis. In K. S. Ratcliff (Ed.), Healing Technology Feminist Perspectives (pp. 305-326). Ann Arbor, MI: University of Michigan Press.

Grebner, S., Elfering, A., Semmer, N. K., Kaiser-Probst, C., and Schlapbach, M. L. (2004). Stressful situations at work and in private life among workers: An event sampling approach. Social Indicators Research, 67, 11-49.

Gunthert, K. C., Cohen, L. H., and Armeli, S. (1999). The role of neuroticism in daily stress and coping. Journal of Personality and Social Psychology, 77, 1087-1100.

Hofmann, D. A. and Gavin, M. B. (1998). Centering decisions in hierarchal linear models: Implications for research in organizations. Journal of Management, 24, 623-641.

Karasek, R. A. (1979). Job demands, job decision latitude, and mental strain: Implications for job redesign. Administrative Science Quarterly, 24, 285-307.

Karasek, R. and Theorell, T. (1990). Healthy Work: Stress, Productivity, and the Reconstruction of Working Life. New York: Basic Books.

Kreft, I. (1996). Are Multilevel Techniques Necessary? An Overview, Including Simulation Studies. Los Angeles, CA: California State University.

Kreft, I. G., Leeuw, J. D., and Aiken, L. S. (1995). The effect of different forms of centering in hierarchical linear models. Multivariate Behavioral Research, 30, 1-21.

Lepore, S. J., Evans, G. W., and Palsane, M. N. (1991). Social hassles and psychological health in the context of constant crowding. Journal of Health and Social Behavior, 32, 357-367.

Lorr, M. and McNair, D. (1982). Profile of Mood States-B. San Diego, CA: Educational and Industrial Testing Service.

Maas, C. J. M. and Hox, J. J. (2002). Robustness of multilevel parameter estimates against small sample sizes [CD-Rom]. In J. Blasius, J. Hox, E. de Leeuw, and P. Schmidt (Eds.), Social Science Methodology in the New Millennium. Opladen, Germany: Leske and Budrich.

Marmot, M., Theorell., T., and Siegrist, J. (2002). Work and coronary heart disease. In Stress and the Heart: Psychological Pathways to Coronary Heart Disease (pp. 50-71). Spain: BMJ Publishing.

Mason, J. H., Anderson, J. J., Meenan, R. F., Weaver, A. L., and Haralson, M. A. (1990). Do life stressors influence disease activity in RA? Arthritis Care and Research, 3, S9.

Meenan, R. F, Yelin, E. H., Nevitt, M., and Epstein, W. V. (1981). The impact of chronic disease: A sociomedical profile of RA. Arthritis and Rheumatism, 24, 544-549. 
Nahit, E. S., Pritchard, C. M., Cherry, N. M., Silman, A. J., and Macfarlane, G. J. (2001). The influence of work related psychosocial factors or regional musculoskeletal pain: A study of newly employed workers. Journal of Rheumatology, 28, 1378-1384.

Parker, J., Frank, R., Beck, N., Finan, M., Walker, S., Hewett, J. E., Broster, C., Smarr, K., Smith, E., and Kay, D. (1988). Pain in RA: Relationship to demographic, medical, and psychological factors. Journal of Rheumatology, 15, 433-437.

Pearlin, L. I. and Schooler, C. (1978). The structure of coping. Journal of Health and Social Behavior, 19, 2-21.

Peeters, M. C. W., Buunk, B. P., and Schaufeli, W. B. (1995). Social interactions, stressful events and negative affect at work: A micro-analytic approach. European Journal of Social Psychology, 25, 391-401.

Persson, L. O. and Sahlberg, D. (2002). The influence of negative illness cognitions and neuroticism on subjective symptoms and mood in rheumatoid arthritis. Annals of Rheumatic Diseases, 61, 1000-1006.

Pfeiffer, C., Affleck, G., and Tennen, H. (1986). Social support and mood state in RA. Arthritis and Rheumatism, 29, S10.

Pope, D. P., Silman, A. J., Cherry, N. M., Pritchard, C., and Macfarlane, G. J. (2001). Association of occupational physical demands and psychosocial working environment with disabling shoulder pain. Annals of Rheumatic Diseases, 60, 852-858.

Potter, P. T., Smith, B. W., Strobel, K. R., and Zautra, A. J. (2002). Interpersonal workplace stressors and well-being: A multi-wave study of employees with and without arthritis. Journal of Applied Psychology, 87, 789-796.

Raudenbush, S. W. and Bryk, A. S. (2002). Hierarchical Linear Models: Applications and Data Analysis Methods, 2nd edn. Thousand Oaks, CA: Sage Publications.

Raudenbush, S. W., Bryk, A. S., Cheong, Y. F., and Congdon, R. T. (2000). HLM5. Hierarchical Linear and Non-Linear Modeling. Lincolnwood, IL: Scientific Software International.

Redfield, J. and Stone, A. A. (1979). Individual viewpoints of stressful life events. Journal of Consulting and Clinical Psychology, 47, 147-154.

Reicherts, M. and Pihet, S. (2000). Job newcomers coping with stressful situations: A micro-analysis of adequate coping and well-being. Swiss Journal of Psychology, 59, 303-316.

Reisine, S., Fifield, J., and Winkelman, D. K. (1998). Employment patterns and their effect on health outcomes among women with rheumatoid arthritis followed for 7 years. Journal of Rheumatology, 25, 1908-1916.

Reisine, S., McQuillan, J., and Fifield, J. (1995). Predictors of work disability in rheumatoid arthritis patients: A five-year follow-up. Arthritis and Rheumatism, 38, 1630-1637.

Repetti, R. (1993). Short-term effects of occupational stressors on daily mood and health complaints. Health Psychology, 12, 125-131.

Schanberg, L. E., Anthony, K. K., Gil, K. M., and Maurin, E. C. (2003). Daily pain and symptoms in children with polyarticular arthritis. Arthritis and Rheumatism, 48, 1390-1397.

Schnall, P. L., Schwartz, J. E., Landsbergis, P. A., Warren, K., and Pickering, T. G. (1998). A longitudinal study of job strain and ambulatory blood pressure: Results from a three-year follow-up. Psychosomatic Medicine, 60, 697-706.

Schwartz, J. E., Pickering, T. G., and Landsbergis, P. A. (1996). Work-related stress and blood pressure: Current theoretical models and considerations from a behavioral medicine perspective. Journal of Occupational Health Psychology, 1(3), 287-310.

Siegrist, J. (2002). Effort-reward imbalance at work and health. Historical and Current Perspectives on Stress and Health, 2, 261-291.

Smith, B. W. and Zautra, A. J. (2002). The role of personality in exposure and reactivity to interpersonal stress in relation to arthritis disease activity and negative affect in women. Health Psychology, 21, 81-88. 
Smith, C. A., Wallston, K. A., and Dwyer, K. A. (1995). On babies and bathwater: Disease impact and negative affectivity in the reports of persons with rheumatoid arthritis. Health Psychology, 14, 64-73.

Soderfelt, B., Soderfelt, M., Jones, K., O'Campo, P., Muntaner, C., Ohlson, C. G., and Warg, L. R. (1997). Does organization matter? A multilevel analysis of the demand-control model applied to human services. Social Science Medicine, 44, 527-534.

Sonnentag, S. (2000). Work, recovery, and individual well-being: A diary study. Journal of Occupational Health Psychology, 6(3), 196-210.

Stewart, W. and Barling, J. (1996). Daily work stress, mood and interpersonal job performance: A mediational model. Work and Stress, 10, 336-351.

Stone, A. A. and Neale, J. M. (1982). Development of a methodology for assessing daily experience. Environment and Health, 4, 49-83.

Stone, A., Reed, B., and Neale, J. (1987). Changes in daily event frequency precede episodes of physical symptoms. Journal of Human Stress, 13, 70-74.

Taylor, S. E. (1991). Asymmetrical effects of positive and negative events: The mobilization-minimization hypothesis. Psychological Bulletin, 110(1), 67-85.

Tennen, H. and Affleck, G. (2002). The challenge of capturing daily processes at the interface of social and clinical psychology. Journal of Social and Clinical Psychology, 21, 610-627.

Tennen, H., Affleck, G., Urrows, S., and Higgins, P. (1992). Perceiving control, construing benefits, and daily processes in rheumatoid arthritis. Canadian Journal of Behavioural Science, 24, 186-203.

Van Eck, M., Nicolson, N. A., and Berkhof, J. (1998). Effects of the stressful daily event on mood states relationship to global perceived stress. Journal of Personality and Social Psychology, 75, 1572-1585.

Wall, T. D., Jackson, P. R., Mullarkey, S., and Parker, S. K. (1996). The demands-control model of job strain: A more specific test. Journal of Occupational and Organized Psychology, 69, 153-166.

West, S. G. and Hepworth, J. T. (1991). Statistical issues in the study of temporal data: Daily experiences. Journal of Personality, 59, 609-662.

White, M., Wrigley, M., Lagory, J., Fine, P., Maisiak, R., and Straaton, K. (1995). The effect of return to work on depression among unemployed persons with arthritis and related musculoskeletal disorders. Arthritis and Rheumatism, 38, S316.

Yelin, E. R, Nevitt, M., and Epstein, W. V. (1980). Toward an epidemiology of work disability. Milbank Memorial Fund Quarterly/Health and Society, 58, 386-415.

Zautra, A., Burleson, M. H., Matt, K. S., Roth, S., and Burrows, L. (1994). Interpersonal stress, depression, and disease activity in rheumatoid arthritis and osteoarthritis patients. Health Psychology, 13, 139-148. 